\title{
Ecoturismo e Educação Ambiental nas trilhas guiadas no Vale do Capão (BA)
}

\section{Ecotourism and Environmental Education on guided trails in Vale do Capão (BA, Brazil)}

Tatiane Evaristo da Silva, Maria Cristina Crispim, Maristela Oliveira de Andrade, Paloma de Sousa Regala

RESUMO: O artigo objetiva discutir o ecoturismo com foco na educação ambiental, tomando o caso das trilhas ecológicas realizadas em um dos principais destinos turísticos do Brasil, o Parque Nacional da Chapada Diamantina (PNCD). Com a finalidade de contribuir com o fomento de uma perspectiva de educação ambiental nas atividades ecoturísticas foi oferecida uma formação para os guias da Associação de Condutores de Visitantes do Vale do Capão (ACV-VC), localizada no distrito Caeté-Açu, no município de Palmeiras/BA. Trata-se de uma Investigação de Ação Participante (IAP) que se constituiu em três etapas: 1. aplicação de um questionário estruturado, no qual objetivou-se recolher informações sobre o conhecimento dos guias sobre ecoturismo, educação ambiental e a conduta deles nas trilhas; 2. realização de um curso de formação, através de apresentação dos conceitos de ecoturismo, bem como a sua aplicação a partir de uma perspectiva de Educação Ambiental (EA); 3. Aplicação do questionário estruturado, novamente, como uma forma de identificar se houve mudanças na percepção dos guias, antes e após o curso de formação. A pesquisa contou com a participação de 11 condutores/guias inscritos através do Sistema Integrado de Gestão de Atividades Acadêmicas (SIGAA), em uma ação conjunta que uniu uma pesquisa científica de mestrado e um projeto de extensão, apenas 9 condutores/guias finalizaram o curso. Ao final da pesquisa, conclui-se que, embora o Vale do Capão seja um dos destinos mais procurados como opção ecoturística, não há clareza sobre os princípios do ecoturismo, por parte dos condutores/guias nas trilhas ecológicas, o que dificulta a efetivação das finalidades do ecoturismo. Após a realização do curso notou-se uma mudança na percepção dos condutores/guias, que passaram a compreender o ecoturismo nas diversas dimensões: Educação/Conscientização e Conservação ambiental, demonstrando a importância da realização de formações continuadas nesses espaços.

Palavras-Chave: Ecoturismo; Trilhas Guiadas; Educação Ambiental; Vale do Capão; Parque Nacional da Chapada Diamantina.

Sociedade Brasileira de Ecoturismo. Rua Dona Avelina, 225, Vila Mariana, São Paulo, SP - Brasil.368 E-mail: zneiman@gmail.com; Tel. (55-11) 99195-7685. 
ABSTRACT: The article aims to discuss ecotourism, in the relationship between tourists and guides, on the ecological trails made in one of the main tourist destinations in Brazil, the Chapada Diamantina National Park (PNCD), through a training that had the purpose of contributing to the promotion of a perspective of environmental education in ecotourism activities carried out by the Association of Visitor Guides of Vale do Capão (ACV-VC), located in the Caeté-Açu district, in Palmeiras / BA. It is a Participatory Action Investigation (PAI) resulting from part of a research, at the master's level, which consisted of three stages: 1. application of a structured questionnaire, in which the objective was to collect information about the guides' knowledge on ecotourism, environmental education and their conduct on the trails; 2. conducting a training course, through the presentation of ecotourism concepts, as well as its application from an Environmental Education (EE) perspective; 3 . Application of the structured questionnaire, again, as a way to identify if there were changes in the guides' perception, before and after the training course. The survey was attended by 11 conductors/guides registered through the Sistema Integrado de Gestão de Atividades Acadêmicas (SIGAA), in a joint action that brought together a scientific master's research and an extension project, only 9 conductors/guides completed the course. At the end of the research, it is concluded that, although Vale do Capão is one of the most sought after destinations as an ecotourism option, there is no clarity about the concepts of ecotourism, on the part of conductors/guides on ecological trails, which makes it difficult to carry out the purposes of ecotourism. After the course, there was a change in the perception of conductors/guides, who began to understand the concept of ecotourism in the different dimensions: Education/Awareness and Environmental Conservation, which concludes the importance of carrying out continuous training in these spaces.

KEYWORDS: Ecotourism; Guided Trails; Environmental Education; Vale do Capão; Chapada Diamantina National Park.

\section{Introdução}

A procura por atividades recreativas em ambientes naturais e a estruturação dos Parques Nacionais tendem a trazer impactos decorrentes do turismo, tanto para a economia nacional, quanto local. De acordo com o secretário nacional de Integração Interinstitucional do Ministério do Turismo (Mtur), a procura por destinos ecoturísticos tem sido uma demanda crescente no Brasil nos últimos anos. Estima-se que a procura estrangeira por passeios ecoturísticos tenha crescido $27,3 \%$, o que coloca o país em primeiro lugar no ranking de competitividade do Fórum Econômico Mundial, no que concerne aos atrativos ligados ao turismo de natureza (MINISTÉRIO DO TURISMO, 2019).

Com a crescente procura, o ecoturismo passa a ocupar um espaço rentável no mercado de turismo, fato que irá impactar significativamente as realidades locais, que concebem o usufruto dos recursos naturais como meio de sobrevivência. Os impactos podem ser observados a partir de uma perspectiva dualista, de um ecoturismo que constrói um lugar, ora concebido para suprir as necessidades financeiras da manutenção dessas áreas, oferecendo recursos importantes para a sua preservação, ora como um ecoturismo palco de conflitos sociais advindos de dinâmicas internas e externas, das complexas relações entre os povos locais e os grandes 
empreendedores que ali se instalam, bem como, da dinâmica entre eles e os turistas que visitam esses locais (ARAÚJO, 2010).

O ecoturismo é mais do que a apropriação dos recursos naturais para fins de turismo e lazer, é, sobretudo, um compromisso com o desenvolvimento sustentável, um turismo que estabelece a sua participação econômica pautada na preservação e conscientização ambiental por meio da educação não-formal. Sobre isso, Ferreira e Coutinho (2010) destacaram como princípios do ecoturismo a conservação do patrimônio ambiental, cultural e a educação ambiental como ferramenta para a formação de uma consciência ambientalista.

As trilhas guiadas, são importantes para a implementação do ecoturismo, pois com elas têm-se informações/ aprofundamento sobre o ambiente visitado, sobre a comunidade local, e a interação com a natureza, que se dá através da interpretação e percepção ambiental. Com isso é necessário que os condutores (popularmente conhecidos e chamados de guias), tenham uma boa formação e também informações sobre o local, de modo a repassar aos turistas durante as trilhas guiadas (REGALA 2013).

Os déficits na condução dos passeios ecológicos podem acarretar a falta de conscientização ambiental, ocasionando, por parte dos turistas, o entendimento de que o ecoturismo se resume às atividades de contato com a natureza, desconsiderando a perspectiva pautada na tríade educação, conservação ambiental e desenvolvimento social (BACKES; RUDZEWICZ, 2012), conforme OECO (2015).

Partindo dessa premissa, este artigo tem por objetivo discutir o ecoturismo, nas trilhas ecológicas realizadas em um dos principais destinos turísticos do Brasil, o Parque Nacional da Chapada Diamantina (PNCD), através de uma formação que teve por finalidade contribuir com o fomento de uma perspectiva de educação ambiental nas atividades ecoturísticas realizadas pela Associação de Condutores de Visitantes do Vale do Capão (ACV-VC), localizada no distrito Caeté-Açu, no município de Palmeiras/BA.

O PNCD é, atualmente, sinônimo de ecoturismo, fato que atrai milhares de turistas à visitação ao parque, todos os anos. Entretanto, Regala (2013), ao realizar um estudo tomando como locus de pesquisa o Vale do Capão, identificou que o grande fluxo de visitantes tem gerado problemas na efetivação dos princípios do ecoturismo, tendo em vista que não há devido cumprimento destes, de maneira satisfatória. O problema em foco diz respeito à condução dos passeios turísticos (pelos diversos guias, sendo eles, integrantes da ACVVC ou não integrantes) pelas trilhas, sendo observado que os turistas não recebem, na maior parte das vezes, instruções/conhecimentos sobre as questões ambientais, o que deixa deficitário a questão da educação Ambiental, intrínseca ao ecoturismo, perdendo este grande potencial (REGALA, 2013).

Este artigo dá continuidade ao estudo de Regala (2013), logo, tem-se como ponto de partida o déficit na formação dos condutores da ACV-VC, no que concerne ao ecoturismo. Como contribuição e retorno à comunidade 
local foi realizado o curso de capacitação para guias de turismo da ACV-VC, através de um projeto de extensão pela Universidade Federal da Paraíba.

Esta pesquisa surgiu com o intuito de contribuir para a formação dos condutores de visitantes no Vale do Capão/BA, partindo do questionamento se os guias do PNCD conhecem os princípios do ecoturismo, mas não o aplicam?

O projeto foi pensado de forma a incentivar a prática de ecoturismo, a partir de estratégias educativas que visavam promover maior conscientização ambiental por meio do repasse de informações em diferentes eixos: a) Conceitos de turismo; b) Desenvolvimento Sustentável; c) Ecoturismo; d) Educação Ambiental; e) Interpretação Ambiental; f) Ecossistemas da Chapada Diamantina. Trata-se dos resultados de uma pesquisa, em nível de mestrado, desenvolvida e vinculada ao Programa de Pós-Graduação em Desenvolvimento e Meio Ambiente (PRODEMA-UFPB).

\section{O ecoturismo na perspectiva da Educação Ambiental}

O segmento ecoturístico, no Brasil, surgiu após a década de 1980, através de conceito introduzido pela EMBRATUR por meio de projeto de turismo ecológico (OECO, 2015). A perspectiva de um modelo de turismo para a preservação ambiental é permeada pelas reivindicações dos movimentos globais ambientais que podem ser observados ainda na década de 50 através de manifestações sociais que passaram a questionar o modelo de sociedade destrutivo, inflado pelo incentivo ao crescimento econômico desenfreado por meio do consumo (RAMOS, 2001). A emergência desse debate, inserido nas manifestações sociais, deu surgimento à primeira Conferência Mundial de Estocolmo, realizada em 1972 pela Organização das Nações Unidas (ONU). No centro do Debate, a relação do homem com o meio ambiente, a degradação ambiental e a importância de se ter como princípio um desenvolvimento econômico atrelado à conservação da natureza (ESTOCOLMO, 1972).

A partir das orientações do evento em Estocolmo, foi realizado, em 1977, a Conferência Intergovernamental sobre Educação Ambiental. A Conferência de Tbilisi teve como foco central o debate sobre as questões ambientais a partir da perspectiva da educação, entendida como estratégia efetiva no processo de conscientização ambiental (SÃO PAULO, 1994). Dentre as recomendações de Tbilisi esteve o entendimento de que a EA é transversal, portanto, deve atingir todos os grupos de idade e categorias profissionais, sendo direcionada:

- ao público em geral, não-especializado, composto por jovens e adultos cujos comportamentos cotidianos têm uma influência decisiva na preservação e melhoria do meio ambiente;

- aos grupos sociais específicos cujas atividades profissionais incidem sobre a qualidade desse meio;

- aos técnicos e cientistas cujas pesquisas e práticas especializadas constituirão a base de conhecimentos sobre 
os quais deve sustentar-se uma educação, uma formação e uma gestão eficaz, relativa ao ambiente. (MINISTÉRIO DO MEIO AMBIENTE, s/d)

O Brasil, como país membro destes acordos internacionais passou a adotar a perspectiva da EA em todos os meios públicos e privados. Nesse sentido, surgiu na década de 80 a Política Nacional do Meio Ambiente (PNMA), implementada através da L6938/1981, que dispõe sobre a obrigatoriedade da EA em todos os níveis de ensino formal, bem como, nãoformal, sendo esta última reservada à capacitação de diferentes comunidades para fins de preservação e defesa do meio ambiente (BRASIL, 1981). Em 1988, a Constituição Federal, em seu art. 225, caput VI, reafirmou e assegurou o compromisso de "promover a educação ambiental em todos os níveis de ensino e a conscientização pública para a preservação do meio ambiente" (BRASIL, 1988, p. 68). A transversalidade da Educação Ambiental é assegurada, mais tarde, através da Política Nacional de Educação Ambiental, implementada pela L9795/1999, no qual o segmento turístico é amplamente influenciado.

Decorre que a tendência mundial de proteção e valorização do meio ambiente, em conformidade com as Leis implementadas, constroem 0 segmento do ecoturismo e o consolidam no país através de diretrizes delineadas pelos eventos mundiais, cita-se ainda a contribuição da Conferência das Nações Unidas para o Meio Ambiente, a ECO 92 (BRASIL, 1992), realizada dez anos após a conferência em Estocolmo, bem como, as políticas nacionais que foram fomentadas a partir dessas Conferências. É mediante essas diretrizes que o ecoturismo se insere, a partir de uma perspectiva de turismo atrelada à preocupação com o desenvolvimento econômico, à degradação do ambiente e com a questão social, através de debates sobre a necessidade da conservação ambiental. Trata-se de um segmento turístico que utiliza o patrimônio natural e cultural de maneira sustentável, de modo a provocar a conservação do meio ambiente e "a formação de uma consciência ambientalista por meio da interpretação do ambiente, promovendo o bem-estar das populações" (BRASIL, 2010. p.17)".

Segundo Kinker (2002), não há como desvincular o ecoturismo da educação ambiental, ambos se relacionam de forma intrínseca, tendo em vista que um dos principais propósitos do ecoturismo está na EA e o que diferencia esse tipo de turismo de natureza dos outros, é o seu caráter educacional. Nessa perspectiva, o ecoturismo deve contemplar todas as populações envolvidas nas atividades ecoturísticas, em uma ação de conscientização ambiental coletiva, que vai, desde a comunidade receptora, até os turistas que visitam as comunidades (KINKER, 2002). É com base nisso, que Ferreira e Coutinho (2010) apontaram para a necessidade da inserção das comunidades anfitriãs como beneficiárias do desenvolvimento dessa atividade. 


\section{O ecoturismo no Vale do Capão}

Insere-se nesta análise o ecoturismo no Vale do Capão/BA (CaetéAçu, nome oficial do distrito de Palmeiras-BA), foco desta pesquisa. Uma comunidade que se reinventou na década de 80 e reestruturou a sua base econômica, outrora cafeeira, através do turismo de natureza com a criação do Parque Nacional da Chapada Diamantina em 1985. O reordenamento social no Vale do Capão gerou um impacto monetário de grande dimensão, não só para a comunidade, mas para todo o município de Palmeiras, fato que ocasionou um processo de expansão local que atraiu pessoas de diferentes lugares do Brasil e do mundo. Em decorrência das novas dinamizações sociais, a partir da década de 1980, o vale vivenciou uma extensão territorial devido à reestruturação da comunidade que, por sua vez, se voltou para o atendimento ao turismo de natureza. O que se observou a partir de então foram construções em diversos segmentos com foco no atendimento exclusivo ao turismo, como pousadas, bares, restaurantes etc. (ARAÚJO, 2010).

As mudanças decorrentes no Vale do Capão estão inseridas no cenário de demandas mundiais pela preservação ambiental, discutidas anteriormente. Este reordenamento social ocorreu em diversas áreas de preservação ao redor do mundo, como por exemplo, na Costa Rica, que a partir da década de 1980 reestruturou sua atividade econômica para atender ao turismo de preservação ambiental, pautado na sustentabilidade e na experiência (FÓRUM DE DESENVOLVIMENTO DO RIO, 2017)

O desenvolvimento econômico voltado para o atendimento do turismo de natureza, principalmente através das trilhas ecológicas que dão acesso às cachoeiras, tornou o Vale do Capão um dos destinos mais conhecidos do Brasil, sendo um dos mais visitados do PNCD. E, por estar situada em uma Unidade de Conservação (UC), a comunidade tradicional é entendida como sinônimo de contato com a natureza, atrelado ao desenvolvimento sustentável, fato que pode pressupor que o lugar é um exemplo de conscientização ambiental. Entretanto, apesar do Vale do Capão ser aparentemente um local em perfeita harmonia com a prática do ecoturismo, Regala (2013), em estudo anterior sobre o ecoturismo no Vale do Capão, constatou que havia necessidade da transmissão de conhecimento, por parte dos condutores dos passeios nas trilhas ecológicas, o que levou a refletir, neste estudo, sobre uma prática educativa capaz de fomentar uma consciência ambientalista, tal como referido nos princípios do ecoturismo (BRASIL, 2010).

O pressuposto é de que o turismo de natureza é uma importante atividade econômica e que se bem planejada pode ser bastante significativa para a comunidade local e os visitantes. Por isso, ações que incentivem a caracterização completa do ecoturismo fazem-se necessárias para que esta atividade no Vale do Capão não seja apenas a realização de trilhas guiadas. Nessa perspectiva essa pesquisa insere-se como meio de contribuir com a questão, através de uma formação em ecoturismo a partir de uma perspectiva de EA não-formal, potencializando a satisfação dos visitantes 
associado ao atendimento do conceito de ecoturismo com o aumento da sensibilização ambiental, conforme apresentado a seguir.

\section{Procedimentos metodológicos}

\section{Local de Estudo}

A pesquisa tem como locus o PNCD (Figura 1), uma Unidade de Conservação criada em 1985, com uma área de 152.000 ha cercada pelos municípios de Lençóis, Palmeiras, Andaraí, Mucugê, lbicoara e Ataetê (BRITO, 2005; ICMBio, 2007). Em sua diversidade ecológica ímpar, o parque possui uma extensão de $300 \mathrm{Km}$ de trilhas que compõem três biomas brasileiros: Mata Atlântica, Cerrado e Caatinga, 33 cachoeiras, 10 locais para escalada, 16 sítios históricos e o Marimbus, conhecido como pantanal da Chapada Diamantina (ICMBIO, s/d).

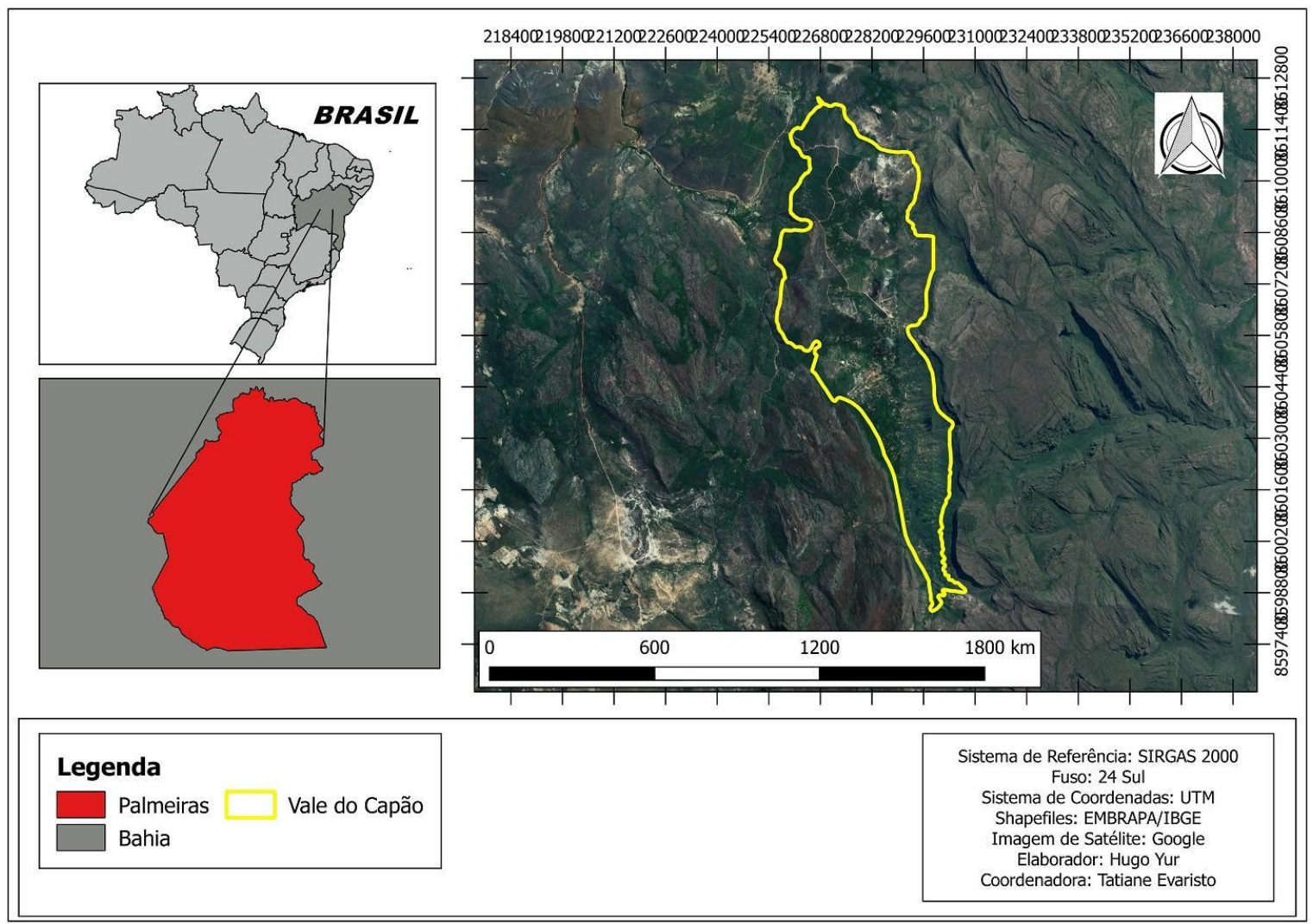

Figura 1: Mapa de Localização do Vale do Capão (Caeté-Açu), Chapada Diamantina, BA Figure 1: Location Map of Vale do Capão (Caeté-Açu), Chapada Diamantina, BA

Fonte: Elaborado por Hugo Yuri e coordenado pela primeira autora com base na imagem satélite de representação geográfica do Vale do Capão, disponível no google.

Source: Prepared by Hugo Yuri and coordinated by the first author based on the satellite image of Vale do Capão's geographic representation, available on google.

Analisa-se a condução de apenas um destes pontos turísticos, a trilha ecológica Cachoeira da Fumaça por cima. Essa trilha ecológica é realizada em uma caminhada de $12 \mathrm{~km}$ de ida e volta em um tempo de 4 horas de ida e volta, numa velocidade média de caminhada de $3,5 \mathrm{Km} / \mathrm{h}$, em uma altitude máxima de 1.350 metros, desnível de 350 metros, sendo a altura da 
cachoeira 380 metros (ACV-VC). A maior parte do caminho da trilha é feita sobre cascalhosas. A vegetação encontrada é de Campo Rupestre, que é considerado uma ilha em Biomas, com uma vegetação de baixo e médio porte, que por algumas vezes já sofreu com as queimadas.

A trilha da Fumaça está situada em Caeté-Açu, mais conhecido como Vale do Capão, uma extensão que abriga cerca de 2.000 habitantes, a 500 $\mathrm{Km}$ da Capital da Bahia, Salvador. O distrito faz parte do município de Palmeiras, com população estimada de 9.071 habitantes (IBGE, 2019). O acesso do centro de Palmeiras ao Capão é feito através de $23 \mathrm{Km}$ de estrada de terra (BRITO 2005; NASCIMENTO, 2008).

\section{A Ação Participante}

A formação foi realizada com os guias da Associação de Condutores de Visitantes do Vale do Capão (ACV-VC), na sede dos associados e também ponto de partida para o início da Trilha da Fumaça. Os guias realizam a trilha com o número máximo de 10 pessoas por condutor, e cobra-se a partir de 80 reais a diária que pode variar de acordo com o número de pessoas do grupo. Na sede também são coletados dados dos turistas havendo um controle de entrada e saída da trilha. Os guias apresentam grau de escolaridade em sua maioria entre ensino fundamental e médio, mas também se encontra nível superior, e pós-graduação enriquecendo o trabalho da equipe.

Para a realização do curso com os condutores optou-se pela abordagem metodológica denominada Investigação de Ação Participante (IAP), que tem por objetivo investigar e atuar no campo de pesquisa para que haja uma contribuição por parte do pesquisador em interação com a comunidade (ORTIZ; BORDAS, 2008). Nesse sentido, a IAP foi realizada com os condutores que atuam diretamente na prática do ecoturismo, através das trilhas, para que estes sirvam como multiplicadores do conhecimento.

As aulas foram presenciais, nas datas 13 e 14 de julho, ministradas pela professora doutora Cristina Crispim co-autora desta pesquisa, com monitoria da primeira e quarta autoras deste artigo. Esta última também condutora de ecoturismo vinculada à Associação de Condutores de Visitantes do Vale do Capão (ACV-VC).

As inscrições dos condutores foram feitas através do Sistema Integrado de Gestão de Atividades Acadêmicas (SIGAA-UFPB) e o curso de capacitação foi promovido pelo Fluxo Contínuo de Extensão (FLUEX) da Universidade Federal da Paraíba (UFPB) que disponibilizou meio de transporte da UFPB com motorista para o deslocamento da ministrante até o local do curso incluindo apoio financeiro para o combustível e as diárias do motorista. Também recebeu apoio da ACV-VC com café da manhã e almoço para os guias participantes do curso e membros da equipe que 0 ministraram.

O curso foi oferecido gratuitamente aos condutores associados da ACV-VC com carga horária de 16 horas distribuídos em aula teórica, aula prática, aplicação de questionário e atividade escrita. No conteúdo teórico do 
curso foram apresentados conceitos atrelados ao ecoturismo, bem como, informações sobre a própria região do PNCD. Para tanto, organizou-se a ementa a partir dos seguintes conteúdos: a) Conceitos de turismo; b) Desenvolvimento Sustentável; c) Ecoturismo; d) Educação Ambiental; e) Interpretação Ambiental; f) Ecossistemas da Chapada Diamantina. A aula teórica ocorreu na sede da ACV-VC que fica na entrada da Trilha da Fumaça no Vale do Capão. O espaço foi oferecido gratuitamente e contou com suporte tecnológico para a parte expositiva do curso com a utilização da data show da associação. As informações completas do curso estão dispostas na Tabela 1:

Tabela 1: Plano de curso de capacitação.

Table 1: Training course plan.

Categoria
Ano de realização
Período de realização da parte teório
envio de relatório
Período de realização da aula de camp
Área temática
Público Alvo
Número de participantes estimado
Número de participantes alcançados
Modalidade do curso
Carga horária
Espaço realizado

Objetivo do curso

Conteúdo trabalhado

Resultados esperados

Curso de capacitaça

Curso de capacitação

2017

06/09/2017 a 30/09/2017

13/07/2017 a 14/07/2017

Meio ambiente

Condutores de Visitantes (guias) do Vale do Capão/ Chapada Diamantina

20

10

Presencial

$16 \mathrm{hrs}$

Associação de Condutores de Turismo da Chapada Diamantina

Capacitar os guias de turismo para o ecoturismo

- Conceitos de turismo

- Desenvolvimento Sustentável

- Ecoturismo

-Educação Ambiental

- Interpretação Ambiental

- Ecossistemas da Chapada Diamantina

Aplicação do ecoturismo por parte dos guias nas trilhas ecológicas, de modo a melhorar a percepção e consciência ambiental dos visitantes através da aplicação da educação ambiental.

Fonte: SIGAA/UFPB

Source: SIGAA/UFPB

O conteúdo prático do curso ocorreu na trilha da Cachoeira da Fumaça em que a ministrante apresentou aos condutores uma prática pedagógica de EA não-formal, por meio da percepção ambiental com os visitantes, assim como a aplicação da interpretação ambiental. Uma das atividades de percepção ambiental consistia no silenciar, fechar os olhos e sentir a natureza, em seguida expor o que cada um sentiu, escutou, cheirou. O mesmo se repetiu para outros sentidos, usando a máquina fotográfica como ferramenta, em que cada um registrava o que achava bonito, diferente, 
importante, e no final mostrar-se-iam as fotos, com as diferentes perspectivas de cada um.

No início do curso foi aplicado um questionário (Tabela 2) com os guias, para recolher informações sobre o conhecimento deles sobre ecoturismo, educação ambiental e a conduta deles nas trilhas.

Tabela 2: Questionário aplicado antes e depois do curso de ecoturismo para guia.

Table 2: Questionnaire applied before and after the ecotourism course for guides.

\section{Questionário}

1- Na sua opinião, que tipo de turismo é realizado na Chapada Diamantina?

2- Você explicaria o ecoturismo como sendo o quê?

3- Você aplica o ecoturismo? () sim () não () não sei

4- Quando você guia as pessoas nas trilhas, você repassa informações sobre o ambiente? ()

$\operatorname{sim}()$ não

5- Que estratégias você usa para repassar esses conhecimentos?

6- Você considera que realiza Educação Ambiental com os visitantes? Sim () Não ( )

7- Como você acha que poderia melhorar essa transmissão de conhecimentos?

Fonte: Elaborado pelas autoras

Source: Elaborated by the authors

Ao final do curso o mesmo questionário foi aplicado, para fins de comparação, o intuito era analisar a percepção dos condutores antes e após a realização da formação. Foi solicitado aos guias participantes, a elaboração de um relatório como requisito para obtenção dos certificados

\section{Resultados e discussão}

Os resultados da Investigação de Ação Participativa (IAP) realizada através de um curso de capacitação de ecoturismo para guias da Associação de Condutores de Visitantes desta comunidade serão apresentados a seguir.

Com o apoio da colaboradora local, que também é guia associada da ACV-VC, foi possível a realização do curso com a participação de 11 condutores inscritos, destes, 9 concluíram a parte teórica e prática do curso e receberam certificado através do Fluex UFPB.

A primeira atividade do curso, antes da aula expositiva (Figura 2), foi a aplicação do questionário citado anteriormente, com o objetivo de identificar o conhecimento dos guias sobre o local de trabalho, ecoturismo, educação ambiental, e sua conduta nas trilhas. Das 7 perguntas compostas no questionário, 3 eram objetivas e 4 eram abertas, 


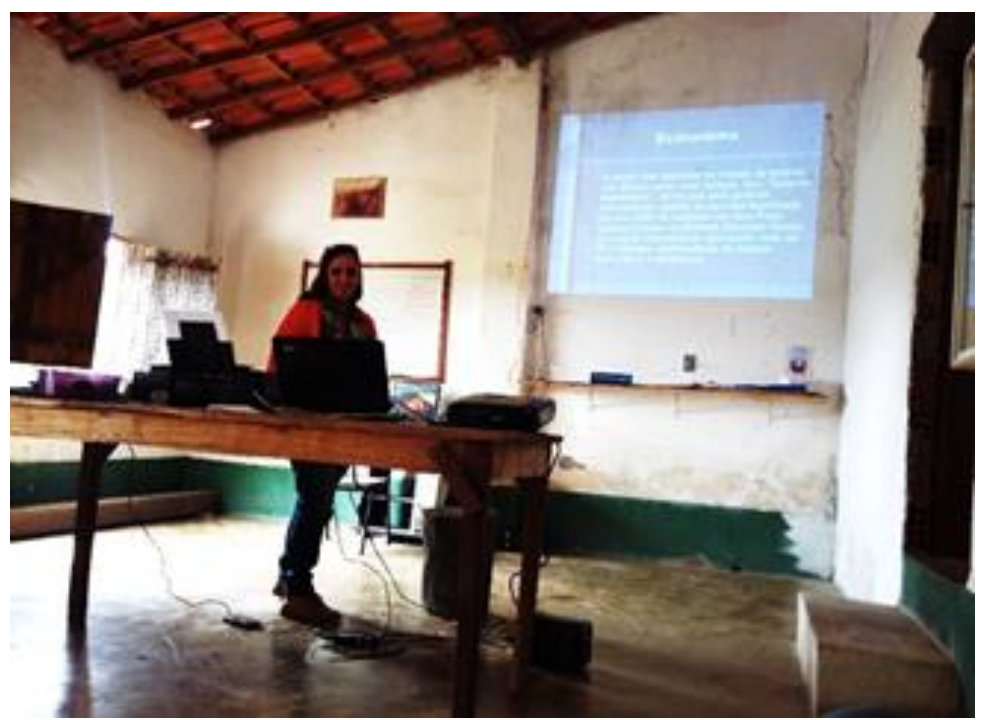

Figura 2: Aula teórica do curso de capacitação ecoturismo para guias na sede da ACV-VC, no Vale do Capão, BA. Fonte: Acervo da autora, 2017.

Figure 2: Theoretical class of the ecotourism training course for guides at the of ACV-VC, in Vale do Capão, BA. Source: Author's collection, 2017.

Um dado que chamou a atenção, durante o processo de formação, é que havia uma ideia incutida nos condutores, de que eles aplicavam o ecoturismo no Vale do Capão, e isto foi afirmado por eles no questionário. Ao serem questionados "você aplica o ecoturismo?", quase $100 \%$ da amostra confirmou a apropriação do conceito em suas trilhas ecológicas. Entretanto, ao observar as suas falas, no momento de interação do curso, foi detectada uma limitação na concepção do ecoturismo, resumida à noção de contato com a natureza, sendo necessário investir no processo de conscientização ambiental via transmissão do conhecimento da área visitada.

Com a análise das questões discursivas, verificou-se outra realidade que já tinha sido detectada por Regala (2013), que há pouca transmissão de conhecimento, por parte dos condutores/guias, relacionado com 0 ecossistema. A ausência de conhecimento necessário ocasiona um déficit no repasse de informações para os visitantes, que reproduzem a concepção de que passeios ecoturísticos são atividades que se resumem ao contato com a natureza, como fora identificado na pesquisa de Backes e Rudzewicz (2012) sobre a experiência de ecoturismo no Parque Estadual de Itapuã/ RS. Consequentemente, o visitante perde a oportunidade de compreender a importância do lugar em suas dinâmicas sociais, conforme defendido por Araújo (2010), por se tratar de um patrimônio natural e cultural e, logo, há importância de defendê-lo e preservá-lo, conforme disposto (BRASIL, 2010).

A falta de repasse de informação aos visitantes coloca em xeque a aplicação da premissa do tripé do ecoturismo, pautado na educação/interpretação, desenvolvimento social/econômico e conservação. Também compromete o próprio desenvolvimento local e o objetivo das unidades de conservação, tendo em vista que um dos princípios, assegurados pela L9985/2000 (SNUC) é "XII - favorecer condições e promover a educação e interpretação ambiental, a recreação em contato 
com a natureza e o turismo ecológico (BRASIL, 2000), um turismo atrelado à EA, ou melhor, ecoturismo;

A clareza sobre o conceito de ecoturismo, por parte dos guias, foi analisada a partir das questões 1 e 2. Questionou-se, a priori, a perspectiva dos guias sobre o tipo de turismo realizado na Chapada Diamantina. Ao analisar as respostas representadas na tabela 3 observa-se que há uma mudança na percepção antes e após o curso de formação. Nessa questão os guias pontuaram:

Tabela 3: Tipo de turismo ofertado no PNCD segundo os guias.

Table 3: Type of tourism offered in the PNCD according to the guides.

Na sua opinião, que tipo de turismo é realizado na Chapada Diamantina?

\begin{tabular}{ccc}
\hline Tipo de Turismo & Antes do curso & Depois do curso \\
\hline Turismo de aventura & 5 & 2 \\
Ecoturismo & 2 & 6 \\
Turismo Cultural & 2 & 1 \\
Turismo de visitação à & 1 & 1 \\
natureza & 1 & 2 \\
Turismo explorador & 1 & 1 \\
Turismo Sustentável & 1 & \\
\hline
\end{tabular}

Fonte: Dados da pesquisa, 2017.

Source: Research data, 2017.

Ao analisar a Tabela acima, percebe-se que há uma contradição nas respostas dos guias, no que concerne ao entendimento, apropriação do conceito e prática do ecoturismo nas trilhas ecológicas. Ora, quase $100 \%$ da amostra confirmou que tinha domínio conceitual do ecoturismo, entretanto, ao serem questionados sobre qual o tipo de turismo predominante no PNCD, alegam ser o turismo de aventura. Portanto, questionou-se: os guias dominam o conceito de ecoturismo, mas não o aplicam? Ou, as contradições expostas refletem a falta de apropriação conceitual do ecoturismo? Ou melhor, os guias entendem a efetivação do ecoturismo, nas trilhas ecológicas, apenas como uma parte do turismo ofertado no PNCD, sendo as problemáticas exteriores às trilhas, para além de suas capacidades? São algumas das questões levantadas.

Antes da formação apenas dois entrevistados alegaram que o PNCD oferece ecoturismo em suas trilhas, sendo o turismo de aventura escolhido pela maior parte dos entrevistados. Após o curso, há uma queda no número de guias que citam o turismo de aventura e um aumento na menção do ecoturismo. Há mudança também na menção sobre o Turismo Cultural e o Turismo "explorador". Identifica-se ainda que os condutores estão se atualizando em cursos como Primeiros Socorros, Geologia, História, entre outros, mas não haviam tido cursos sobre a prática do Turismo ou Ecoturismo. 
É preciso salientar, todavia, que apesar da palavra ecoturismo ser citada 8 vezes nas respostas, sendo 6 após o curso, o termo é mencionado como uma forma de dizer que ainda não há ecoturismo ou que há pouco, no sentido de que, nem todos o aplicam, conforme alegado pelos guias. Assim sendo, os guias mencionam após o curso que o PNCD está tentando ofertar um ecoturismo, que ainda não o é, segundo observado nas respostas:

Tabela 4: Respostas sobre que tipo de turismo ofertado no PNCD, segundo os guias das trilhas do Vale do Capão (BA), após a realização do curso.

Table 4: Answers on what kind of tourism offered at the PNCD, according to the Vale do Capão (BA) trail guides, after the course was completed.

\section{Comentários acerca do turismo ofertado no PNCD}

Guia1 (pós): Turismo de Visitação à Natureza, com um pouco de ecoturismo e um pouco de turismo de aventura.

Guia 3 (pós): Turismo ainda explorador, mas tentando transformar em ecoturismo.

Guia 4 (pós): Turismo Nativo pouco ecoturismo

Guia 5 (pós): O turismo aqui é mais exploratório onde poucas pessoas fazem realmente o ecoturismo.

Fonte: Dados da pesquisa, 2017.

Source: Research data, 2017

Considerando que a compreensão do ecoturismo não deve ser fragmentada, mas baseada na relação entre interpretação-conservaçãodesenvolvimento local, pautada em uma educação ambiental, conclui-se que a maior parte dos guias não aplica o ecoturismo em suas trilhas, daí a importância dos cursos de formação.

O Vale do Capão é reconhecido hoje como um modelo de turismo sustentável e isso é enxergado em sua dinâmica social, de preservação do patrimônio através de sua culinária típica, da arquitetura, da arte, dos costumes tradicionais, da medicina naturalista, das vivências esotéricas, da apicultura (ARAÚJO, 2010). Todavia, há uma limitação sobre as finalidades dos passeios ecoturísticos. O PNCD é tido como um dos destinos mais procurados do Brasil, é uma forma de se distanciar do barulho das cidades, entretanto, questiona-se quais têm sido os impactos do ecoturismo, por meio das trilhas seriam minimizados se houvesse maior sensibilização e conscientização ambiental dos visitantes após a visita a estes lugares? Ou, em contrapartida, têm sido compreendidos apenas como alternativas diferenciadas de lazer, um turismo de aventura, como disposto pelos guias antes da formação?

Daí a importância de pensar a formação dos guias, tendo em vista que são eles que estabelecem contato direto com os visitantes, portanto, são os principais mediadores no processo de conscientização ambiental e os principais multiplicadores do conhecimento. A necessidade de formação continuada é uma estratégia primordial no processo de implementação do 
ecoturismo em unidades de conservação, no sentido de consolidar a ideia de uma conservação, conforme os objetivos da Lei 9.985 (2000) no Art. 4ํㅜㄴ, entre os quais o de promover a educação e interpretação ambiental e o turismo ecológico (BACKES; RUDZEWICZ, 2012).

É importante promover a prática do ecoturismo na Chapada Diamantina, porque este turismo além de ser mais sustentável, proporciona o aprendizado dos visitantes sobre o ambiente visitado, aumentando a percepção e sensibilização ambientais, essenciais para uma mudança de postura em relação ao ambiente e na formação de pessoas mais educadas ambientalmente, objetivos direcionados para a criação das Unidades de Conservação.

Os resultados considerando o antes e o depois da realização do curso (Tabela 5) mostram nitidamente a efetividade das formações, pois ao serem questionados sobre a compreensão do ecoturismo, percebe-se uma mudança na percepção dos guias sobre o conceito, mudança que se atribui à realização da formação:

Tabela 5: Compreensão do ecoturismo segundo os guias.

Table 5: Understanding ecotourism according to the guides.

\begin{tabular}{|c|c|c|}
\hline \multicolumn{3}{|c|}{ Você explicaria o ecoturismo como sendo o quê? } \\
\hline $\begin{array}{c}\text { O que é } \\
\text { ecoturismo? }\end{array}$ & Antes do curso & Depois do curso \\
\hline $\begin{array}{l}\text { Turismo com } \\
\text { Educação Ambiental }\end{array}$ & 1 & 4 \\
\hline $\begin{array}{l}\text { Turismo com } \\
\text { conscientização } \\
\text { ambiental }\end{array}$ & 2 & 5 \\
\hline $\begin{array}{l}\text { Turismo para } \\
\text { preservação } \\
\text { ambiental }\end{array}$ & 1 & 3 \\
\hline
\end{tabular}

Fonte: Dados da pesquisa, 2017.

Source: Research data, 2017.

Ao analisar os dados expostos na Tabela 5 salienta-se sobre a necessidade da formação continuada, pois a Política Nacional de Educação Ambiental, instituída pela L9795, é datada de 1990, ainda assim, existe pouco conhecimento de que a EA é indissociável do ecoturismo. Viu-se que poucos guias compreendiam o ecoturismo a partir da EA, fato que denota as contradições existentes entre aquilo que é assegurado pela Lei e o que de fato é efetivado no cotidiano da prática.

Após o curso de formação, foi possível observar uma melhoria na definição do conceito de ecoturismo, e isto pôde ser verificado através da associação de ecoturismo como educação ambiental, conscientização ambiental e preservação ambiental. Há uma mudança significativa na 
compreensão do ecoturismo, principalmente no que concerne às suas finalidades. Antes apenas 1 guia entendia que o ecoturismo estava atrelado à $E A$, após o curso esse número passou para 4, o mesmo ocorre com a conscientização ambiental, que passou de 2 para 5 respostas (o que representou $100 \%$ dos alunos para a percepção que EA e conscientização fazem parte do ecoturismo), e o turismo para conservação, que passou de 1 para 3, após a formação.

O fato dos guias do Vale do Capão ainda não terem bem estabelecidos os princípios de ecoturismo pode interferir nas atividades realizadas. Nesse sentido, acredita-se na necessidade de uma interação educativa com os mesmos, visto que não tinham recebido capacitação para a aplicação do ecoturismo. Consequentemente, atividades relacionadas com as questões ambientais, como educação/conscientização/conservação ambiental, eram negligenciadas e o repasse de informações sobre o bioma, para aumentar a sensibilização ambiental eram esparsos.

$\mathrm{Na}$ aula prática do curso os guias tiveram a oportunidade de observar a ministrante assumindo o papel de condutora (Figura 3), e mostrando como pode ser trabalhada a interpretação e a percepção ambiental, método utilizado para fomentar uma linguagem comum entre homem e natureza (CARVALHO; CRISPIM, 2018). Carvalho e Crispim (2018) discutem a importância da inserção da EA nas trilhas ecológicas através da interpretação ambiental, as autoras concluem que:

As áreas de conservação são locais ideais para a aplicação da educação ambiental (EA) e no próprio SNUC é apresentada a EA como forma de uso possível na maioria das UCs. O ecoturismo tem a EA como um dos objetivos da proposta, e usando a ferramenta de interpretação ambiental, que otimiza a transferência de informações, será capaz de aumentar o conhecimento adquirido ao longo da visitação e com isso contribuir com o aumento da consciência ecológica dos visitantes (CARVALHO; CRISPIM, 2018, p. 851)

A aula prática (Figura 3) foi realizada na trilha da Fumaça, um dos principais pontos turísticos do Capão. Nesse momento também houve espaço para discussões e sugestões dos guias para o melhor desempenho das atividades já realizadas na trilha.

Sobre a conduta e repasse de informações e conhecimento acerca do ambiente houve a discussão sobre a relação do ICMBio com a ACV-VC e foi relatado a necessidade de capacitação e apoio por parte do órgão federal responsável pela gestão do Parque. Percebeu-se que os guias precisam de mais informações sobre os Biomas da Chapada Diamantina que acometem principalmente os locais em que estes realizam as trilhas. $O$ estudo de Câmara e Lima (2017) mostrou que o uso adequado das trilhas ecológicas, na formação dos guias, fortaleceu os conceitos de sustentabilidade na Área de Preservação Ambiental do Inhaum, no município de Caxias-MA. 


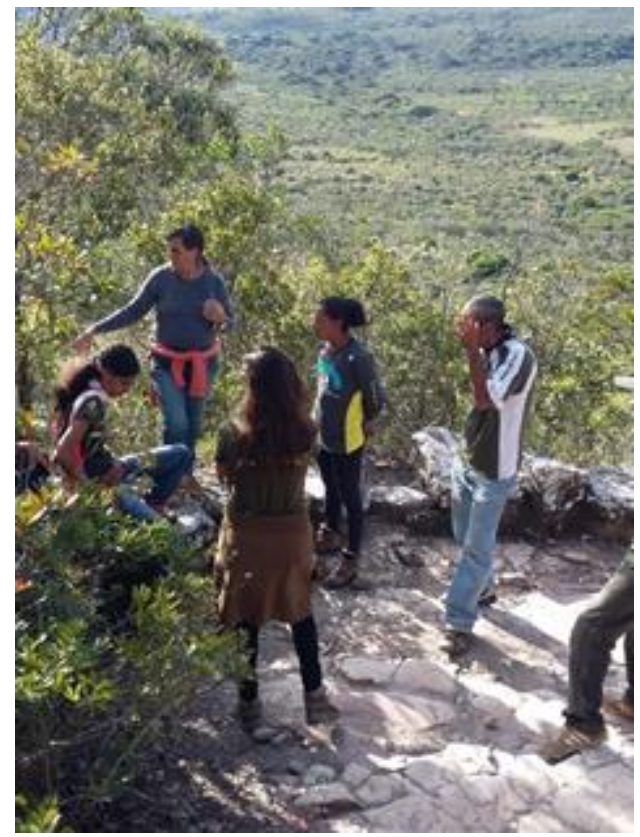

Figura 3: Aula prática do curso de capacitação para guias na Trilha da Fumaça, Vale do Capão, Chapada Diamantina, BA. Fonte: acervo da autora, 2017.

Figure 3: Practical class for the training course for guides on the Fumaça Trail, Vale do

Capão, Chapada Diamantina, BA. Source: author's collection, 2017.

Há muito a ser explorado e a ser discutido em meio às trilhas ecológicas, segundo o estudo de Eisenlohr et al. (2013), as trilhas ecológicas apresentam espaços adequados para projetos de EA permitindo 0 conhecimento para dirimir os impactos da vegetação, podendo ampliar e sensibilizar os ecoturistas nesses ambientes.

Ainda assim, quando os guias questionados sobre quais estratégias utilizam para repassar conhecimentos, a maior parte se limita a informações de senso comum, apenas três guias relataram repassar informações sobre a fauna e a flora do lugar. Apesar de nos questionários não relatarem sobre a fauna e a flora, na aula de campo demonstraram conhecimento popular da vegetação, e apresentaram algumas plantas que normalmente mostram aos turistas, entre elas Candombá (Vellozia sincorana L.B Sm.\& Ayensu), Drosera espécie carnívora, Orquídea (Cattleya sincorana Schltr. Van den Berg), Sempre viva (Helichrysum bracteatum) entre outras.

As respostas, antes do curso, apontaram a necessidade de aprofundamento do conhecimento. Em conversas realizadas durante o curso houve uma sugestão de elaboração de um informativo de bolso sobre o Parque Nacional Chapada Diamantina para ajudar aos guias no repasse de informações. Uma sugestão feita, no momento da capacitação, foi a utilização de recursos didáticos, de acordo com Buzatto e Kuhnen (2020), o uso de jogos pedagógicos e quiz de perguntas e respostas auxiliam na sensibilização e aprendizado dos conceitos ecológicos durante as trilhas, sendo essa uma forma lúdica de aprender sobre o lugar visitado e o seu entorno.

Após o curso, concluiu-se que há necessidade de suporte educativo, e que este deve ser continuado, e poderia ter apoio do ICMBio, responsável 
pela gestão do Parque. Em visita a este órgão, verificou-se haver abertura para a promoção desses cursos. No entanto, mesmo após 3 anos dessa visita, com propostas de aumentar o incentivo e apoio aos guias turísticos do Vale do Capão, nenhum movimento por parte desse órgão foi efetuado. Lembra-se aqui que o trabalho realizado de forma independente pelos guias é uma responsabilidade do órgão gestor da Unidade de Conservação, neste caso o ICMBio. Apesar disso, durante visita pessoal, foi-nos repassado pelos servidores deste órgão as seguintes informações/sugestões:

Programa para desenvolver o cadastro dos guias e criar qualificação constante. Estimativa de mais de 600 guias no Parque e nenhum parque lida com esse número. Não conseguiremos barrar os guias não credenciados, mas vamos divulgar os guias formalizados, seguindo o modelo do Parque Itatiaia (Comunicação pessoal de funcionário do ICMBIO).

Ao final do curso foi realizada uma oficina, em que os guias foram incentivados a apresentar as principais dificuldades, visando contribuir para otimizar e potencializar as atividades de turismo realizadas nas trilhas originadas a partir do Vale do Capão. Nas respostas obtidas no quadro 3, os guias sugeriram aprofundar o conhecimento e as informações a respeito do PNCD. Vejam-se as respostas dos guias com as sugestões para melhorar o repasse do conhecimento:

Tabela 6: Sugestões para melhorar o conhecimento nas trilhas após realização do curso. Table 6: Suggestions for improving knowledge on the trails after taking the course.

\section{Sugestões dos guias}

Guia 1: Melhor conhecimento sobre história e flora.

Guia 2: Através de mais conhecimento que integre o visitante com todo esse contexto.

Guia 3: Pesquisando sobre tudo que engloba o ecoturismo passando para a comunidade e empresários locais e principalmente nas escolas

Guia 5: Estimular os sentidos, instigar a curiosidade fazendo perguntas, jogos, com as cores ao redor, comparar os eventos naturais, com eventos feitos pelo homem.

Guia 7: Fazendo pesquisas, cursos, trocar ideias com colegas de trabalho, conversando com os nativos mais velhos.

Guia 8: Socializar com áreas em geral, com profissionais em geral, bem como a necessidade de introdução do conteúdo ainda como base escolar. Passar o conhecimento de modo prioritário.

Guia 9: Com base na fauna e flora.

Fonte: Pesquisa, 2017.

Source: Research, 2017.

Pelas demandas apontadas acima, da necessidade que os guias sentem de ter acesso a mais conhecimento, comprova-se a importância da 
EA, principalmente no que diz respeito à flora e à fauna da região, o turismo, seus tipos e características. Uma vez preparados, os guias poderão realizar melhor o seu trabalho de multiplicador de EA, e não de "repassador de informações", que vai além de mostrar o caminho da trilha até chegar às cachoeiras. Acredita-se que ao apresentar as características locais com mais detalhes e informações, os visitantes serão bem direcionados para a natureza visitada, facilitando os processos de sensibilização ambiental.

Tal conclusão coaduna com os estudos de Gentile, Franco e Sayago (2016) e Carvalho e Crispim (2018), sobre a importância dos guias nas unidades de conservação. Ao receber formação adequada, o guia torna-se um agente da conservação do parque, cuja atuação contribui de forma geral para o desenvolvimento local por meio da participação na comunidade, e de forma específica através das trilhas guiadas, como mediador do conhecimento, aquele que auxilia o processo de visitação, de modo a proporcionar uma consciência ecológica guiada pela educação/interpretação ambiental, como sugerem os princípios do ecoturismo.

A percepção ambiental é primordial para a prática do ecoturismo, compondo com a finalidade da unidade de conservação, enquanto espaço delimitado para atividade produtiva, de uso econômico controlado (Zoneamento ambiental). Exemplos de UC podem ser observados nas experiências ecoturísticas do Parque Nacional Marinho de Fernando de Noronha (PE) e nas piscinas naturais de Maragogi (AL) (DIEGUES, 2001; DEBEUS; CRISPIM, 2008; SANTOS et. al. 2013;).

Outro aspecto a ser salientado na oficina, foi o fato das crianças da própria comunidade não terem acesso ao conhecimento local e às peculiaridades da natureza no seu entorno. Após o curso, os guias passaram a ver a comunidade de forma ampla. Chegou-se à ideia de que os mais antigos e, portanto, com mais conhecimentos, poderiam repassar 0 saber local para os guias, o que valoriza o lugar. No município de Alto Paraíso, no Goiás, e Vila de São Jorge, na Chapada dos Veadeiros, desde a década 1990 são realizados cursos de formação para guias e profissionais do turismo. Nestas formações, os guias anciãos enriquecem a oferta formativa em parceria com ONGs, fundações nacionais e internacionais, órgãos federais e estaduais. (GENTILE, FRANCO E SAYAGO, 2016) o que poderia ser realizado também em Vale do Capão, com o conhecimento empírico dos mais velhos sendo valorizado e repassado para os guias de turismo desta localidade.

\section{Conclusão}

A Educação ambiental em áreas de parques cumpre o papel de gerar uma preocupação ambiental, por parte dos visitantes, que, ao serem bem orientados sobre as finalidades das UC, tendem a respeitar os limites impostos pelo plano de manejo, se assim houver, o que acarreta no cumprimento de sua função.

Considera-se, ao final do trabalho realizado, que houve uma boa aceitação do curso por parte dos guias, com poucos desistentes em relação 
ao número de guias inscritos (apenas dois desistiram, logo no início) por incompatibilidade de horários. E necessário pontuar que há necessidade de continuidade na formação dos guias, com vista ao fortalecimento da concepção de ecoturismo atrelado à educação ambiental, ainda mais, ao considerar que a finalidade do curso era de fomentar estratégias pedagógicas para a sua prática, associada ao turismo.

Chama-se a atenção para o baixo quantitativo de guias inscritos, quando o número de guias é bem maior, cerca de 52 vinculados à ACV-VC, no Vale do Capão, fato que pode pressupor uma falta de disponibilidade para a formação, pela maior parte dos associados, ou falta de interesse pelo assunto.

Os guias que se dispuseram a participar do curso têm boa intenção em transmitir informação e difundir a educação ambiental como é prevista na lei federal das Unidades de Conservação, neste caso em Parque Nacional. Mas, já foi comprovado que não são todos os guias que assumem esse compromisso. Como o curso foi gratuito, não se pode citar a dificuldade financeira em realizá-lo como motivo de ausência dos condutores de visitantes ao mesmo.

Concluiu-se que, embora o Vale do Capão seja um dos destinos mais procurados como opção ecoturística, os condutores/guias das trilhas ecológicas não revelaram clareza no conhecimento sobre os princípios de ecoturismo, o que dificulta a efetivação das suas finalidades. Entretanto, após a realização do curso notou-se uma mudança na percepção dos condutores/guias, que passaram a compreender o ecoturismo a partir dos pilares da Educação/Conscientização, Desenvolvimento local e Conservação ambiental, bem como a importância da realização de formações continuadas nesses espaços.

O conhecimento e a transmissão das informações sobre os biomas da Chapada Diamantina poderiam existir com o apoio do ICMBio com sede em Palmeiras, que tem equipe qualificada, como Botânico, Ecólogo, entre outros profissionais, para ministração de cursos de capacitação para os guias que atuam diretamente no Parque. Outra possibilidade seria a parceria entre as Universidades e os Institutos Federais, de modo a trazerem professores dispostos a darem suporte ao conhecimento dos guias que atuam no Parque Nacional Chapada Diamantina, como ocorreu nesta ação realizada como parte da pesquisa de mestrado da primeira autora.

Os guias assumem um importante papel na conservação do Parque, e como tal carecem de uma atenção especial por parte dos órgãos responsáveis pela Unidade de Conservação. É necessário que consigam mais apoio institucional, seja por órgãos governamentais locais, seja pelo ICMBio, seja pelos empresários de meios de hospedagem, visto que, se os visitantes se hospedam lá é porque tem um atrativo que foi criado e é mantido pelos guias.

Cabe salientar a importância do papel desenvolvido pela ACV-VC, que é o único órgão a realizar o censo de visitação de turistas na Chapada Diamantina, que seria da responsabilidade do órgão gestor do parque, 
desenvolvendo atividades extremamente relevantes para a gestão do turismo no local. Os guias são responsáveis pela recepção dos turistas, logo, recai sobre eles a responsabilidade em proporcionar uma experiência ecoturística na perspectiva da $E A$, mas como o farão se não há neles uma percepção ambiental desenvolvida? Daí a necessidade das formações continuadas, como verificado.

Havendo maior integração entre todos os atores envolvidos no turismo realizado no Vale do Capão, a atividade de ecoturismo poderia ser efetivada, aumentando o potencial do local e garantindo um maior aproveitamento para o visitante de conscientização ambiental. Para além disso, com o conhecimento adquirido os guias podem gerar maior satisfação aos visitantes, que divulgará mais a atividade ecoturística no Parque.

\section{Agradecimentos}

Agradecemos ao apoio fornecido pelo Centro de Ciências Exatas e da Natureza, Fluxo Contínuo de Extensão (FLUEX) da Universidade Federal da Paraíba (UFPB) e Associação de Condutores de Visitantes do Vale do Capão (ACV-VC). Agradecemos especialmente a bióloga Jane Enisa Torelli de Souza pelo suporte na documentação do curso. Agradecemos ao apoio institucional do Programa de Pós-Graduação em Desenvolvimento e Meio Ambiente (PRODEMA/UFPB). Agradecemos pela bolsa de mestrado fornecida pela Coordenação de Aperfeiçoamento de Pessoal de Nível Superior (CAPES) à primeira autora.

\section{Referências}

ARAÚJO, L.C. A Sustentabilidade Trilheira do Vale do Capão/ Palmeiras-BA. Revista de Desenvolvimento Econômico, ano XIII, v12, n22. Salvador: UNIFACS. 2010.

BRASIL. Constituição da República Federativa do Brasil. Promulgada em 5 de outubro de 1988. Brasília: 2017. Versão impressa. Edição administrativa do texto constitucional.

BRASIL. Lei $n^{\circ} 6.938$ de 31 de agosto de 1981. Dispõe sobre a Política Nacional do Meio Ambiente, seus fins e mecanismos d e formulação e aplicação, e dá outras providências Disponível em: <http://www.planalto.gov.br/ccivil 03/leis/l6938.htm> Acesso: 01/07/2020

BRASIL. Lei $\mathbf{n}^{\circ} \mathbf{9 . 9 8 5}$ de 18 de julho de 2000. Institui o Sistema Nacional de Unidades de Conservação da Natureza e dá outras providências. Disponível em:

<http://www.planalto.gov.br/ccivil 03/leis/l9985.htm\#: :text=LEl\%20No\%209. 985\%2C\%20DE\%2018\%20DE\%20JULHO\%20DE\%202000.\&text=Regulam enta\%200\%20art.,Natureza\%20e\%20d\%C3\%A1\%20outras\%20provid\%C3\% AAncias. > Acesso: 01/07/2020

BRASIL. Ministério do Meio Ambiente. Recomendações da Tbilisi. Disponível em: <https://www.mma.gov.br/informma/item/8065recomenda\%C3\%A7\%C3\%B5es-de-tbilisi.htm> acesso: 01/07/2020 
BRASIL. Ministério do Turismo. Ecoturismo: Orientações Básicas. $2^{\circ}$ edição. Brasília, DF, Ministério do Turismo, 2010. Disponível em: http://www.turismo.gov.br/sites/default/turismo/o ministerio/publicacoes/dow nloads publicacoes/Ecoturismo Versxo Final IMPRESSxO .pdf Acesso: 01/07/2020

BACKES, L.; RUDZEWICZ, L. A Visão dos Turistas sobre a Experiência de Ecoturismo no Parque Estadual de Itapuã - RS. Anais do VII Seminário de Pesquisa em Turismo do Mercosul. Caxias do Sul, RS: 2012. Disponível em: $<$ https://www.ucs.br/site/midia/arquivos/a visao dos turistas.pdf > acesso: 01/07/2020

BUZATTO, L.; KUHNEN, C.F.C. Trilhas interpretativas uma prática para a educação ambiental. Revista Vivências. Erechim-RS, v. 16, n. 30, p. 219231 | jan./jun. 2020.

CÂMARA, J.T.; LIMA, A.R. O uso de Trilhas Ecológicas para Trabalhar Educação Ambiental. Educação Ambiental em Ação, v. 16, n 59 mar-mai, 2017.

CAVALCANTI, A. Ecoturismo, Meio Ambiente e Sustentabilidade: Análises e propostas. In: SEABRA, G. Educação Ambiental no Mundo Globalizado: Uma ecologia de riscos, desafios e resistência. João Pessoa: Editora Universitária/UFPB, 2011.

CARVALHO, I.B.P.; CRISPIM, M.C. Proposta de criação de uma trilha ecológica como forma de aproveitamento econômico de Áreas de Proteção Permanente (APP): Fazenda Serra Grande e o Caminho das Águas. Revista Brasileira de Ecoturismo, São Paulo, v.10, n.4, jan. 2018, pp.831-855.

DEBEUS, G.; CRISPIM, M.C. O turismo nas piscinas naturais de Picãozinho, João Pessoa, PB - percepções, conflitos e alternativas. Revista de estudos ambientais REA, v.10, n. 1, p. 21-32, jan./jun. 2008.

DIEGUES, A. C. Ecologia Humana e Planeamento Costeiro. São Paulo: NUPAUB, 2001.

EISENLOHR, P.V.; MEYER, L.; MIRANDA P.L.; S.; REZENDE, V.L.; SARMENTO, C.D.S.; MOTA T.J.R.C.; GARCIA, L.C.; MELO, M.M.R.F. Trilhas e seu papel ecológico: o que temos aprendido e quais as perspectivas para a restauração de ecossistemas? Hoehnea. São Paulo, v. $40, n^{\circ} 3$, p. 407-418, 2013

ESTOCOLMO. Declaração da Conferência das Nações Unidas sobre o Meio Ambiente Humano. Estocolmo, 1972. Disponível em: $<$ https://apambiente.pt/ zdata/Politicas/DesenvolvimentoSustentavel/1972 D eclaracao Estocolmo.pdf> Acesso: 08/10/2019.

FERREIRA, L.F. COUTINHO, M.C.B. Ecoturismo: a importância da Capacitação Profissional do Condutor Ambiental Local. In: ARLINDO, P.J. Gestão Ambiental e Sustentabilidade no Turismo. Barueri: Manole, 2010. (Coleção Ambiental, v. 9)

FÓRUM DE DESENVOLVIMENTO DO RIO. Ações que alavancaram o turismo da Costa Rica são apresentadas no Fórum, 2017. Disponível em: 
$<$ https://www.querodiscutiromeuestado.ri.gov.br/noticias/5038-acoes-quealavancaram-o-turismo-da-costa-rica-sao-apresentadas-no-forum>. Acesso em: 08/09/2020.

GENTILE, C.; FRANCO, J.L.A.; SAYAGO, D.A.V. Um Modelo de Capacitação Rumo à Sustentabilidade: Os guias de Alto Paraíso de Goiás Chapada dos Veadeiros (GO). Fronteiras: Journal of Social, Technological and Environmental Science • v.5, n.1, p. 168-185, jan.-jun. 2016.

SÃO PAULO (Estado). Secretaria do Meio Ambiente. Declaração da Conferência Intergovernamental sobre Educação Ambiental. In: Educação Ambiental e Desenvolvimento: documentos oficiais. São Paulo, Secretaria do Meio Ambiente, 1994. p. 28-30 Disponível em: $<$ http://arquivos.ambiente.sp.gov.br/cea/cea/EA DocOficiais.pdf>. Acesso: 12 de out. de 2020

GUZZATTI, T.C.; SAMPAIO, C.A.C.; CORIOLANO, L.N.M.T. Turismo de base comunitária em territórios rurais: caso de Associação de Agroturismo Acolhida na Colônia (SC). Revista Brasileira de Ecoturismo, São Paulo, v.6, n.1, jan/abr-2013, p 93-106.

ICMBIO. Parque Nacional da Chapada Diamantina. Disponível em: $<$ https://www.icmbio.gov.br/portal/visitacao1/unidades-abertas-a-

visitacao/9396-parque-nacional-da-chapada-da-diamantina>. Acesso: 06/07/2020.

KINKER, S. Ecoturismo e conservação da natureza em parques nacionais. Campinas/ São Paulo: Editora Papirus, 2002.

MARCONI, M.A.; LAKATOS, E.M. Técnicas de Pesquisa: planejamento e execução de pesquisas, amostragens e técnicas de pesquisa, elaboração e análise e interpretação de dados. 7.ed. São Paulo: Atlas, 2015.

MINISTÉRIO DO TURISMO. MTur destaca importância do ecoturismo para economia brasileira. Disponível em: $<$ http://www.turismo.gov.br/\%C3\%BAltimas-not\%C3\%ADcias/12864-turismodestaca-import\%C3\%A2ncia-do-ecoturismo-para-economia-brasileira.html> acesso: $01 / 07 / 2020$

OECO. 0 que é ecoturismo. Disponível em: <https://www.oeco.org.br/dicionario-ambiental/28936-o-que-e-ecoturismo/> Acesso: 01/07/2020

ORTIZ, M.; BORJAS, B. La Investigación Acción Participativa aporte de Fals Borda a la educación popular. Espacio Abierto Cuaderno Venezolano de Sociologia. Zulia. v17, n 4, p. 615-627, out-dez/2008,

RAMOS, E.C. Educação ambiental: origem e perspectivas. Educar. Curitiba: Editora da UFPR, pp.201-218, 2001

REGALA, P.S. Contribuições para o Planejamento Ecoturístico na Trilha da Fumaça por cima, no Vale do Capão - Parque Nacional da Chapada Diamantina/BA. 2013. Dissertação (mestrado). Programa de Pós- 
Graduação em Desenvolvimento e Meio Ambiente, Universidade Federal da Paraíba, João Pessoa, 2013.

SANTOS, J.S.; LOURENÇO, L.J.S.; CRISPIM, M.C.; ELOY, C.C. Percepção ambiental dos visitantes do Parque Estadual Marinho de Areia Vermelha, Cabedelo, PB. Anais do III Encontro Nacional de Educação Ambiental e V Encontro Nordestino de Biogeogafia (2013, João Pessoa). João Pessoa: p. 707-712, 2013.

Tatiane Evaristo da Silva: Universidade Federal da Paraíba, João Pessoa, PB, Brasil.

E-mail: tatieevatur@gmail.com

Link para o currículo Lattes: http://lattes.cnpq.br/4590864719924929

Maria Cristina Crispim: Universidade Federal da Paraíba, João Pessoa, PB, Brasil.

E-mail: ccrispim@hotmail.com

Link para o currículo Lattes: http://lattes.cnpq.br/1103302506132951

Maristela Oliveira de Andrade: Universidade Federal da Paraíba, João Pessoa, PB, Brasil.

E-mail: andrademaristela@hotmail.com

Link para o currículo Lattes: http://lattes.cnpq.br/7202471430678926

Paloma de Sousa Regala: Universidade Federal da Paraíba, João Pessoa, PB, Brasil.

E-mail: paloma.tur@hotmail.com

Link para o currículo Lattes: http://lattes.cnpq.br/2229835932905263

Data de submissão: 25 de novembro de 2020

Data de recebimento de correções: 29 de novembro de 2021

Data do aceite: 19 de março de 2021

Avaliado anonimamente

Verificou-se que os mesmos passaram a entender melhor o conceito de ecoturismo e demonstraram interesse em aplicar as metodologias apresentadas no curso, conforme ver-se-á adiante. Também $f$ 